\title{
Effect of nifedipine and mefruside on renal reserve in hypertensive patients
}

\author{
A. Notghi and J.L. Anderton \\ Medical Renal Unit, Western General Hospital, Crewe Road, Edinburgh EH4 2XU, UK.
}

\begin{abstract}
Summary: Changes in glomerular filtration rate and effective renal plasma flow following a protein meal were measured in seven patients with esssential hypertension on no treatment and after 6 weeks' treatment with nifedipine and mefruside. Glomerular filtration rate and effective renal plasma flow increased significantly following a protein meal in patients on no treatment $(P<0.01$ and $P<0.05$ respectively). The response to a protein meal was lost following antihypertensive treatment $(P<0.5$ and $P<0.1$ respectively). Although there was some increase in the fasting values of glomerular filtration rate and effective renal plasma flow this was less pronounced and more difficult to demonstrate when only fasting values were compared. We propose that the loss of response to a protein meal is due to recruitment of renal reserve function and that protein meal challenge is a sensitive test for detecting changes in renal function.
\end{abstract}

\section{Introduction}

Single high protein meal has been demonstrated to increase the renal blood flow (RBF) in animals. ${ }^{1,2}$ Prolonged dietary protein manipulation and intravenous amino acid infusion has also been shown to change glomerular filtration rate (GFR) and RBF in man,,$^{3,4}$ and recently there has been increasing interest in the changes in GFR and RBF with a single high protein meal. ${ }^{5}$ We have used these changes induced by protein meal to assess the effect of antihypertensive treatment with nifedipine and mefruside on renal function and renal homeostasis.

\section{Patients and method}

Seven patients (age 35-60) with essential hypertension were studied. All had diastolic blood pressure of more than $100 \mathrm{mmHg}$ at two separate clinics before entering this trial and had normal blood urea, electrolytes and haemoglobin. None of the patients had oedema or ascites. Patients with prostatism or bladder dysfunction were excluded from the study. The patients were fully informed about the nature and purpose of the study which was approved by the Lothian ethics committee.

All the patients were maintained on their normal diet for the duration of the trial. Dietary protein was assessed by dietary history, which showed an average protein content of $60 \mathrm{~g} /$ day. Following an overnight fast they were admitted to hospital at

Correspondence: A. Notghi M.D., M.R.C.P., Medical Renal Unit, Western General Hospital, Crewe Road, Edinburgh EH4 2XU, UK.
$09.30 \mathrm{~h}$. They were kept in the recumbent position throughout the study. At $10.00 \mathrm{~h}$ an infusion of inulin and para-amino hippurate (PAH) in $500 \mathrm{mb}$ $5 \%$ dextrose was commenced following a bolus injection. The patients were then encouraged tos drink water to maintain good urinary output (range 130 to $480 \mathrm{ml} /$ hour). At $12.00 \mathrm{~h}$ a meal containing $30 \mathrm{~g}$ of animal protein (roast beef sandwich) was served. Inulin and PAH clearances were measured for one hour before and one hour immediately after the meal using hourly blood samples and spontaneously passed urine volume, urine concentrations and plasma concentrations. ${ }^{6,7}$ Glomerular filtration rate (GFR) was defined as inulin clearance, and effective renal plasma flow (ERPF) was calculated from PAH clearance. GFR and ERPF were measured after 3 weeks on placebo and repeated after 6 weeks' treatment with nifedipine retard $20 \mathrm{mg}$ twice daily and mefruside (a thiazide diuretic) $25 \mathrm{mg} /$ day. GFR and ERPF are expressed in $\mathrm{ml} / \mathrm{min} / 1.73 \mathrm{~m}^{2}$ of body surface area.

The results are expressed as mean \pm standard error of mean (s.e.m.). The two tailed $t$-test is used for comparison of paired data.

\section{Results}

There was a significant reduction in supine systolic blood pressure following 6 weeks' treatment with nifedipine and mefruside from $178 \pm 4.2 \mathrm{mmHg}$ to $148 \pm 5.5 \mathrm{mmHg} \quad(P<0.001)$. There was a similar reduction in diastolic blood pressure from

(C) The Fellowship of Postgraduate Medicine, 1988 
$105 \pm 3.6 \mathrm{mmHg}$ to $89 \pm 3.7 \mathrm{mmHg}(P<0.001)$. The patient weights remained stable throughout the trial $(80 \pm 4.7 \mathrm{~kg})$. The blood urea, electrolytes and haemoglobin remained unchanged during the period of the trial.

Fasting GFR on placebo treatment ranged from 29 to $112 \mathrm{ml} / \mathrm{min} / 1.73 \mathrm{~m}^{2}$ (mean $60.9 \pm 10.9$ ). Following the protein meal there was a significant rise in GFR to $78.7 \pm 9.3 \mathrm{ml} / \mathrm{min} / 1.73 \mathrm{~m}^{2}(P<0.01)$. There was also a significant rise in ERPF from $277 \pm 63.1$ (range 30 to 583 ) to $451 \pm 90.7 \mathrm{ml} / \mathrm{min} /$ $1.73 \mathrm{~m}^{2} ; P<0.05$ ) (Figure 1). After 6 weeks on treatment with nifedipine and mefruside, GFR change with protein meal was lost (fasting $84.2 \pm 10.8$ to post-prandial $77.8 \pm 10.6 \mathrm{ml} / \mathrm{min} /$ $\left.1.73 \mathrm{~m}^{2}, P<0.5\right)$. The change in ERPF is similarly lost after antihypertensive treatment (from fasting level of $434 \pm 82.4$ to post-prandial level of $369 \pm 72.6 \mathrm{ml} / \mathrm{min} / 1.73 \mathrm{~m}^{2}, P<0.1$ ) (see Figure 2).

When fasting values between placebo and treatment periods were compared, although there was an increase in GFR from $60.9 \pm 10.9$ to $84.2 \pm 10.8 \mathrm{ml} / \mathrm{min} / 1.73 \mathrm{~m}^{2}$ and in ERPF from $277 \pm 63.1$ to $434 \pm 82.4 \mathrm{ml} / \mathrm{min} / 1.73 \mathrm{~m}^{2}$, these changes did not reach a statistically significant level $(P<0.1)$. This was mainly due to one patient whose fasting GFR and ERPF fell during the study period. He had an initial urea of $8 \mathrm{mmol} / \mathrm{l}$, which subsequently rose to 12.5 with creatinine reaching a maximum of $120 \mu \mathrm{mol} / 1$.

\section{Discussion}

An abnormal renal response in glomerular filtration
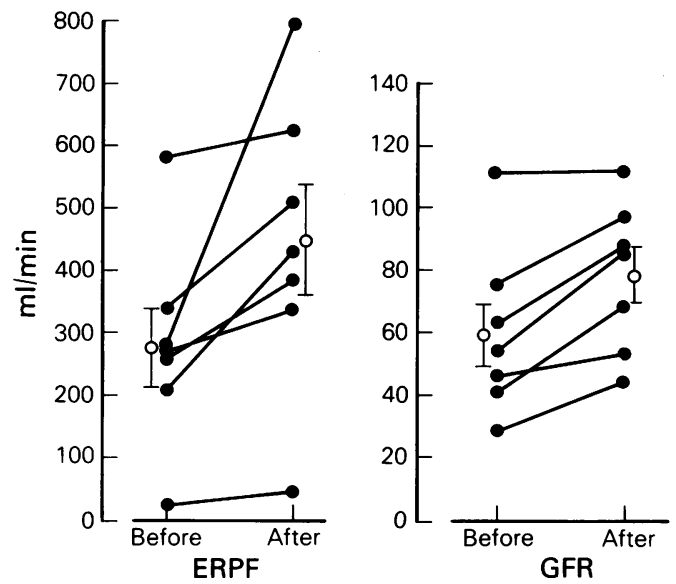

Figure 1 Effect of protein meal on glomerular filtration rate (GFR) and effective renal plasma flow (ERPF) in hypertensive patients on no treatment ( $n=7, P<0.01$ and $P<0.05$ respectively).
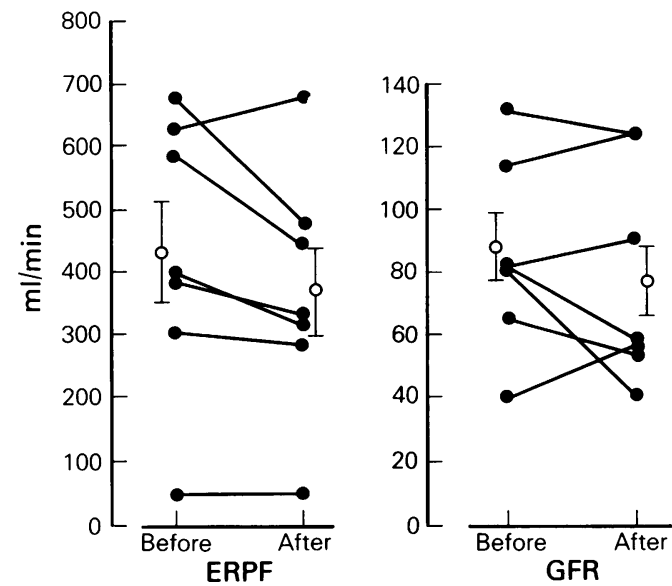

Figure 2 Effect of protein meal on glomerular filtration rate (GFR) and effective renal plasma flow (ERPF) following 6 weeks' treatment with nifedipine and mefruside $(n=7, P=\mathrm{NS})$.

rate and renal blood flow to physiological stimuli, emotion and vasodilators has been demonstrated in patients with essential hypertension. ${ }^{8-10}$ It has been suggested that altered renal perfusion contrio butes to maintenance of high blood pressure ans its pathogenesis in essential hypertension ${ }^{11-1}$ Normalization of renal function by various agents could have a favourable effect in control of hypertension and on long term renal function. Thus it would be important to monitor the effects of antihypertensive agents on renal function. The exaggerated response of GFR and ERPF to stimuli may account for the changes we detected with relatively lower protein load than previously suggested.

Fasting GFR and ERPF are used as a standard test to monitor renal function. More recently a notion of renal function reserve has been developed. ${ }^{5}$ It is postulated that this reserve is important for normal function of kidney and that its loss on a long term basis may contribute to renal function derangement and eventual failure. ${ }^{5,14}$ The mechanism underlying these changes is not fully understood, but it is possibly related to a circulating effector.

We have looked at the combination therapy with nifedipine and a diuretic, as in practice we have often used this combination to achieve satisfactory blood pressure control in hypertensive patients. In a previous study we showed that nifedipine and mefruside did not change the fasting basal renal function in hypertensive patients. ${ }^{15}$ In the present study we have looked at changes in renal function induced by a protein meal in patients with a wide 
range of renal function and demonstrated a significant loss in this response with administration of antihypertensive agents. This loss in renal function reserve seems to be due to an increase in basal ERPF and GFR by recruiting reserve function, as the basal fasting values increased in all but one patient. This patient had imminent renal failure with a creatinine of $120 \mu \mathrm{mol} / \mathrm{l}$ at the end of the study. A combination of renal failure and low urine output $(130 \mathrm{ml} / \mathrm{h})$ may have lead to an erroneous estimation of renal function, as demonstrated by calculated filtration fraction of over $90 \%$. Exclusion of these probably erroneous data confirms the significant increase $(P<0.01)$ in the basal GFR and ERPF levels with the treatment regimen. This suggests that the recruitment of renal reserve may indeed account for the loss of response to protein meal at the end of the study.

There have been conflicting data on effect of calcium antagonists on renal function. Johns ${ }^{16}$ has demonstrated a significant increase in basal renal blood flow in rats following an infusion of nifedipine but no change in GFR. On the other hand MacLaughlin et al. ${ }^{17}$ have shown a significant increase in GFR in hypertensive rats following verapamil infusion while there was no change in renal blood flow. It has been postulated that these

\section{References}

1. Hiatt, E.P. \& Hiatt, R.B. The effect of food on the glomerular filtration rate and renal blood flow in the harbor seal (Phoca vitulina L.). J Cell Physiol 1942, 19: 221-227.

2. O'Connor, W.J. \& Summeril, R.A. The effect of meal of meat on glomerular filtration rate in dogs at normal urine flows. $J$ Physiol 1976, 256: 81-91.

3. Pullman, T.N., Alvin, A.S. \& Dem, R.J. The influence of protein intake on specific renal function in normal man. J Lab Clin Med 1954, 44: 320-332.

4. Cochran, S.T., Pagani, J.J. \& Barbaric, Z.L. Nephromegaly in hyperalimentation. Radiology 1979, 130: 603-606.

5. Bosch, J.P., Saccagi, A., Lauer, A., Ronco, C., Belledonne, M. \& Glabman, S. Renal function reserve in humans: effect of protein intake on glomerular filtration rate. $A m J$ Med 1983, 75: 943-950.

6. Notghi, A., Merrick, M.V., Ferrington, C. \& Anderton, J.L. A comparison of simplified and standard methods for the measurement of glomerular filtration rate and renal tubular function. $B r J$ Radiol 1986, 59: 35-39.

7. Pearson, R.M. Methods for the assessment of the effects of drugs on renal blood flow. Br J Clin Pharmacol 1979, 7: 129-138.

8. Hollenberg, N.K. \& Adams, D.F. The renal circulation in hypertensive disease. Am J Med 1976, 60: 773-784. differences are due to preferential effects of different doses of calcium antagonists on efferent and afferent arterioles in kidney and also due to the difference in patient groups studied. ${ }^{18}$ Conflicting data can also be exaggerated by the relative insensitivity of traditional fasting function tests. It is now recognized that the standard fasting renal function assessment is an insensitive way of measuring renal disease. ${ }^{19,20}$ It would require a larger number of patients to demonstrate this recruitment of renal reserve if only fasting GFR and ERPF are measured.

In our study we detected a significant loss of renal functional reserve following treatment with nifedipine and mefruside in hypertensive patients. The most likely explanation is an increase in basal GFR and renal blood flow with treatment by using some of the renal reserve, and thus reducing the available reserve required for the physiological response to a protein meal.

\section{Acknowledgements}

We would like to thank the renal laboratory staff of the Royal Infirmary of Edinburgh for measurement of PAH and inulin concentrations and Nurse L. Paton for her assistance in performing the clearance tests.

9. Hollenberg, N.K., Williams, G.H. \& Adams, D.F Essential hypertension: abnormal renal vasculature and endocrine response to mild psychological stimuli. Hypertension 1981, 3: 11-17.

10. Wolf, S., Pfeiffer, J.B., Ripley, H.S., Winter, O.S. \& Wolf, H.G. Hypertension as a reaction pattern to stress: variation in blood pressure and renal blood flow. Ann Intern Med 1948, 29: 1056-1076.

11. Kaplan, N.M. The Goldblatt Memorial Lecture: Part II: The role of kidney in hypertension. Hypertension 1979, 1: 456-461.

12. Ferris, T.F. The kidney and hypertension. Arch Intern Med 1982, 142: 1889-1895.

13. Hollenberg, N.K., Borucki, L.J. \& Adams, D.F. The renal vasculature in early essential hypertension: evidence for pathogenetic role. Medicine (US) 1978, 57: $167-178$.

14. Brenner, B.M., Meyer, T.W. \& Hostetter, T.H. Dietary protein intake and the progressive nature of kidney disease; the role of hemodynamically mediated glomerular injury in the pathogenesis of progressive glomerular sclerosis in aging, renal ablation and intrinsic renal disease. $N$ Engl $J$ Med 1982, 307: 65)-659.

15. Notghi, A., Fiskerstrand, C.E., Burnet, M.E. \& Anderton, J.L. Effect of nifedipine and mefruside on renal function and platelet function in hypertensive patients. Curr Med Res Opin 1987, 10: 441-449. 
16. Johns, E.G. The influence of diltiazem and nifedipine on renal function in rat. $\mathrm{Br} J$ Pharmacol 1985, 84: 707-713.

17. MacLaughlin, M., De Mello Aires, M. \& Malnic, G. Verapamil effect on renal function of normotensive and hypertensive rats. Renal Physiol 1985, 8, 112-119.

18. Sorkin, E.M., Clissold, S.P. \& Brogden, R.N. Nifedipine: a review of its pharmacodynamic and pharmacokinetic properties, and therapeutic efficacy, in ischaemic heart disease, hypertension and related cardiovascular disorders. Drugs 1985, 30: 182-274.
19. Bosch, J.P., Laver, A. \& Glabman, S. Short-term protein loading in assessment of patients with renal disease. Am J Med 1984, 77: 873-879.

20. Tapson, J.S., Mansy, H., Marshal, S.M., Tisdall, S.R. \& Wilkinson, R. Renal functional reserve in kidney donors. $Q J$ Med 1986, 60, 725-732. 